\title{
JUDGE ME MORE BY MY FUTURE THAN BY MY PAST
}

\section{Dave Ulrich}

\section{Introduction}

Premature death rites have occurred before. Truman was prematurely declared the loser before he won the 1948 election. Mark Twain, said "Rumors of my death have been seriously exaggerated." Huck Finn attended his own funeral. The 1969 New York Mets were deemed vanished prior to their miraculous comeback and World Series victory. Churchill changed political parties but continued to rebound. Phil Nieckro, the great knuckleball pitcher, was continually counted out but kept returning for another year. John Travolta's career seemed moribund before he reemerged with the leading roles in Pulp Fiction and Phenomenon. Premature deaths occur not only in lifestyles, but in professions.

In the field of human resources (HR), death rites have been proclaimed, eulogies written, and funerals prepared for the demise of the HR function. These eulogies are premature. While HR as we know it (with images of policy police, regulators, and administrative guardians) has passed, a new HR is emerging. If $\mathrm{HR}$ is to play the more significant role many advocate, then the future will have to be characterized by understanding and mastering nine challenges.

\section{HR Matters: Focusing on Deliverables More Than Doables}

On my shelf are 40 years of HR textbooks, each distilling research and synthesizing knowledge. While the content within each chapter has evolved with new research and insight, the basic paradigm has remained the same: The chapter titles continue to be what HR people do, for example, staffing, training, compensation, benefits, appraisal, etc. My view of HR in the future is that we need a new paradigm which focuses less on what HR does and more on what HR delivers. The chapter headings need to be topics such as globalization, customer intimacy, operational excellence, operating margin, and other business strategies. Each chapter can discuss and discover how HR activities accomplish these business goals. The focus, however, should be on the deliverables not the doables.

A similar logic can be applied not only to textbooks but to HR plans. Recently, I visited a world-class company where HR leaders had spent months creating their next year HR plan. They were excited by the new initiatives-competence-based staffing, action learning workshops, leadership development seminars, pay for performance, teambased pay, and employee communications. When asked for an opinion about the quality of this plan, I ventured to ask why-Why were they doing these new initiatives? Why would the business benefit from accomplishing these initiatives? The deliverables were never articulated, so the doables dominated thinking. If other functions used this approach, marketing would allocate its time running focus groups, doing surveys, and segmenting customers rather than on gaining market share and selling products.
If HR is to play the more significant role many advocate, then the future will have to be characterized by understanding and mastering nine challenges. 
As HR focuses on deliverables more than on doables, the paradigm shifts toward creating value more than running programs.

\section{HR Theory: Searching for Why}

Theory explains why things happen they way they do. HR needs theories which explain why HR delivers what it does. For example, in working to reengage employees, HR professionals could draw on intellectual capital theory to specify the value created by each employee to the enterprise and the loss generated when an employee's intellectual capital is either underutilized or underinvested. When discussing why HR practices create results, HR professionals could draw on cognitive theory to describe the importance of a shared mindset which comes from integrated HR practices, they could then demonstrate how shared mindset reduces transaction costs (economic theory), increases ownership (agency theory), and leads to productive communities of employees (community ecology theory).

More pragmatically, HR theory serves two immediate purposes. First, it stops mindless benchmarking or best practice studies by providing an "if. ... then" logic to benchmarking. Most benchmarking focuses on the "then" or the practices engaged by the best practice company without paying any attention to the "if" or context under which the best practice occurs. As a result, firms copy a training, staffing, compensation, or other program which worked in the best practice firm because of series of conditions (the "if"). Theory focuses on why and forces clarity around the if of the "if . . . then" benchmark equation.

Second, theory sets expectations. Theory enables HR to become a profession with a set of standards of what is expected in terms of performance of HR work. Theory leads to respect because a set of standards is articulated and accomplished. Physicians have a theory which leads to standards for medical practice; architects have theories of construction standards; accountants have theories which set standards for the profession. HR needs theory which defines standards.

\section{HR Community: Realizing That HR} Is Not Just for HR

The community of HR needs expansion. The HR community generally includes corporate, field, service center, and center of expertise HR professions-all of whom are within the HR function. In the future, HR will not be accomplished just by those within the HR function but also by line managers, other staff managers, and strategic partnerships with outside vendors.

The HR community needs to create governance mechanisms whereby HR work is done by individuals inside and outside the formal HR function, all dedicated to common outcomes and acting within professional standards. Early outposts of HR communities exist today where HR work is done by line managers (e.g., General Electric is using line managers to teach their executive programs), staff professionals (e.g., Finance and HR have teamed at Fidelity Investments to offer services to business units), and strategic partners (e.g., Many firms have outsourced the administrative, routine, transaction work of $\mathrm{HR}$ ). The ultimate challenge of $\mathrm{HR}$ as a community rather than as a function is to articulate when each member of the community adds value to an external customer.

\section{HR Tools: Mastering HR Practices Not Yet Defined}

The HR function has evolved over the last 40 years, each decade including a new set of HR tools: labor relations and staffing (1940s); training (1950s); regulatory issues, compensation, benefits, appraisal (1960s and 1970s); health care, cost containment, organization design, teamwork, and communication (1980s); mergers, acquisitions, downsizing, diversity (1990s). New tools for HR will be forthcoming. These tools will focus on such areas as: global HR (learning to manage HR issues in global competition), culture change (defining tools for crafting and changing a corporate culture), technology (adapting HR to the ever-changing information highway), leader of the future (defining the competencies of the future, not past leader), and knowledge transfer (understand- 
ing how to generate and generalize knowledge).

These new HR tools will emerge. In the next decade HR professionals will be able to be as explicit about culture change as they are today about the requirements for a successful training program or hiring strategy. Since it is easier to learn than to forget, mastering these new tools will require that old HR tools be more automated, be completed by others in the HR community, and/or be discontinued.

\section{HR Value Chain: Discovering the Real Customer of HR Work}

HR work has generally occurred within the boundaries of the firm. As these boundaries become more permeable, HR work must shift to working across boundaries. For example, traditional programs of staffing, training, and compensation will increasingly include involvement of and focus on suppliers and customers in the firm's value chain. Today, Motorola University attendees are 50\% suppliers and customers of Motorola. In the future, HR work will focus on the value chain as suppliers and customers participate in the design and delivery of HR practices.

These HR value chains may begin slowly; for example, McDonalds, Coca Cola, and Disney are beginning to share information about HR practices. Over time, these chains will likely pick up speed as firms in a value chain collaborate on staffing, training, teamwork, and administrative processes. It might be possible that McDonalds, Coke, and Disney share a training center, a staffing center, an administrative processing center, and career development programs.

\section{HR Value Proposition: Measuring the Impact}

If HR matters, it must be measured. Measuring the impact of HR must be built on breakeven analyses of specific HR programs (e.g., the cost/benefit of a competency based staffing program) to begin to answer such questions as:

- How do HR practices affect the market value of a firm?
- How do HR practices impact the intellectual capital of a firm?

- How can investments in HR practices be directly related to growth, cost, or other financial variables?

- What is the economic impact of using HR practices to create a shared mindset, more efficient transactions, or committed employees?

- What is the economic impact of not investing in HR practices?

In a simple way, efforts to answer these questions will connect investments in $\mathrm{HR}$ practices and business results. So far, HR investments have not been tied clearly to business results, leaving HR with the legacy of being soft, anecdotal, and non-business critical.

\section{HR Careers: Moving from Stages to Mosaics}

A career in HR will not be linear, but will be a mosaic of experiences. Linear models of careers talk about stages for HR professionals; mosaic career models build on diverse experiences inside and outside the function, in field and corporate positions, as generalists and specialists, and in working with strategy and operations. Mosaic careers focus more on what the HR professional knows and is able to do than on title and position. Mosaic careers are more the responsibility of the individual than of the firm. Mosaic careers are expanded when employees take risks and try new things. Mosaic careers prepare HR professionals as business partners more than as functional experts.

\section{HR Competencies: Getting Prepped}

Many in-company studies of the competencies of HR have been done. In addition, some extensive cross-company studies of HR competencies have been performed. As these studies begin to coalesce, four common clusters of competencies of HR professionals are emerging:

- Business knowledge: HR professionals must know the business which includes a mastery of finance, strategy, marketing, and operations.
In the next decade, HR professionals will be able to be as explicit about culture change as they are today about the requirements for a successful training program or hiring strategy. 
In many firms today, downsizing and global competition have left employees feeling more like depreciable than appreciable assets.

The HR of the 80 s is dead; long live the new HR.
- HR state of the art: HR professionals must know the theory and leading edge practices for HR tools.

- Change and process: HR professionals need a model of change and the ability to apply the model to a specific situation.

- Credibility: HR professionals must become personally credible through the accuracy of their work and the intimacy of their relationships.

As these four competencies are turned into behaviors, HR professionals can begin to identify the development and training they require to succeed in the future.

\section{HR and Intellectual Capital: Investing in the Scarce Resource}

Intellectual capital could be seen as another tool area awaiting HR insight, however, I believe it is more than that. Intellectual capital represents the collective insights, knowledge, and commitments of employees within a firm. It can be an asset for investment or a liability for depreciation. Investing in intellectual capital means making sure that employees who are hired with 100 units of competence add to this base annually so that ten years after employment, the original 100 units is now 200, and the 200 are significantly different that the original 100. Depreciating intellectual capital occurs when firms burnout, stress, or demoralize employees.

In many firms today, downsizing and global competition have left employees feeling more like depreciable than appreciable assets; employees often feel less loyalty, commitment, and engagement. In firms of tomorrow, intellectual capital must become an ongoing investment where employees are constantly learning, changing, challenging, and reinventing both themselves and their firms.

HR in the future should play a central role in acquiring, nurturing, and investing in intellectual capital.

\section{Conclusions}

The HR of the 80 s is dead; long live the new HR. This essay ends with optimism because these nine challenges are not insurmountable. They can be debated and defined, and they can be overcome. By so doing, they will frame the HR of the next century. The next-century HR vocabulary will include words such as: deliverables, HR community, HR value chain, HR value proposition, HR governance, culture change, global HR, knowledge transfer, mosaic careers, intellectual capital, creating value. When these words become more than ideas and ideals, then the next generation of HR will have emerged. I hope we can judge HR more by this future than by the past.

Dave Ulrich is Professor of Business Administration at the University of Michigan Business School. He is on the core faculty of the Michigan Executive Program, Co-Director of Michigan's Human Resource Executive Program and the Advanced Human Resource Executive Program. Ulrich studies how organizations change, build capabilities, learn, remove boundaries, and leverage human resource activities. He has generated multipleaward-winning national databases which assess organizational alignment between strategies and human resource practices and HR competencies. He has published over 80 articles and book chapters. He is the Editor Human Resource Management, serves on the editorial board of five other Journals, and writes a monthly column for Human Resource Executive. He is a Fellow in the National Academy of Human Resources and a co-founder of the Michigan Human Resource Partnership; he has been listed by Business Week as one of the world's "top ten educators" in management and the top educator in human resources; and received the Pericles Pro Meritus Award for outstanding contribution to the field of HR. He has consulted and done research with over half of the Fortune 200. 